\title{
Chapter 4 \\ Multitemporal Land Use/Land Cover Change Detection for the Batena Watershed, Rift Valley Lakes Basin, Ethiopia
}

\author{
Gebiaw T. Ayele, Solomon S. Demessie, Kassa T. Mengistu, \\ Seifu A. Tilahun and Assefa M. Melesse
}

\begin{abstract}
A majority of the rural population in Ethiopia depends on agriculture. Land use changes during the past couple of decades are mostly linked to agricultural development attributed to factors such as population pressure and environmental changes. Mapping land use/land cover (LULC) to analyze the type, rate, and extent of changes in land use patterns has far reaching significance for policy/decision makers and resource managers to provoke the wide range of applications at regional scales for erosion, landslide, land planning, forest management, and ecosystem conservation. The focus of this chapter is to depict quick and practical approaches to generate spatially and temporally quantified information on land cover dynamics using high-resolution satellite images for the years (1973-2008) in Batena watershed and its environs in southwestern Ethiopia. To quantify the magnitude of LULC change, supervised classification technique was applied using Landsat Thematic Mapper (TM) and Enhanced Thematic Mapper Plus (ETM+) images employing Bayesian maximum likelihood classifier (MLC) with the aid of ground truth training sites. A majority/minority analysis was used for smoothing the classification results
\end{abstract}

G.T. Ayele $(\bowtie) \cdot$ S.A. Tilahun

Faculty of Civil and Water Resource Engineering, Bahir Dar Institute of Technology,

Bahir Dar University, 252, Bahir Dar, Ethiopia

e-mail: gebeyaw21@gmail.com

G.T. Ayele · S.A. Tilahun

Department of Hydraulic and Water Resources Engineering, Blue Nile Water Institute, Bahir Dar University, 252, Bahir Dar, Ethiopia

S.S. Demessie

Department of Civil \& Environmental Engineering, University of California, Los Angeles, Los Angeles 90095, CA, USA

K.T. Mengistu

Department of Irrigation and Water Resources Engineering, Arba Minch University, Arba Minch, Ethiopia

A.M. Melesse

Department of Earth and Environment, Florida International University, Miami, USA

(C) Springer International Publishing Switzerland 2016

A.M. Melesse and W. Abtew (eds.), Landscape Dynamics, Soils

and Hydrological Processes in Varied Climates, Springer Geography,

DOI 10.1007/978-3-319-18787-7_4 
and the accuracy of image classification was carried out by means of a confusion matrix generated through geographic information system (GIS) overlay of the classified maps and the test samples. The classification accuracy was further verified by the strong kappa statistical estimate of more than $90 \%$ as a measure of overall agreement between image and reference data. The final output of remote sensing imagery revealed five land cover classes: Grazing land, bush land, mixed forest, dominantly cultivated agricultural land, and water body. It has been discovered that, there were more active LULC change processes in the area in the first study period (1973-1984) than the second study period (1984-1995) and the third study period (1995-2003). On the other hand, areal extent of cultivated and uncultivated agricultural land has been on a steady decline from $39.7 \%$ in 1995 to $41.4 \%$ in 2003 and a mere $50.1 \%$ in 2008 . In the first period, nearly half of the landscape underwent land cover change with more than $17 \%$ of the entire landscape experiencing agricultural expansion. In the second period, the extent of the changes was limited to less than $1 / 3$ of the total area with a smaller amount of agricultural area expansion than before. Though the rate of land cover change was observed to vary across the three periods of study, a general decline of forest cover and amplified increase of agricultural lands of more than $41.7 \%$ was found in the area.

Keywords Change detection - Land cover dynamics - Maximum likelihood classifier $\cdot$ Landsat imagery $\cdot$ Remote sensing $\cdot$ GIS $\cdot$ Batena watershed $\cdot$ Ethiopia

\subsection{Introduction}

Land use/land cover (LULC) change has increasingly become a key research priority for national and international research programs examining global environmental change and impact analysis of the changes, which is a standard requirement for land use planning and sustainable management of natural resources as highlighted by many researchers (Petit et al. 2001). Researchers in their finding have argued that more focused management intervention requires information on the rates and impacts of LULC change as well as the distribution of these changes in space and time as a central component in present strategies for managing natural resource and monitoring environmental changes (Tiwari and Saxena 2011). Land use/cover change can affect biodiversity, biogeochemical cycles, soil fertility, hydrological cycles, energy balance, land productivity, and the sustainability of environmental services (Lupo et al. 2001). In most parts of the world, agriculture is the primary driver of land use change. But few comprehensive studies have been undertaken at a global level on long-term historical changes of land cover due to land use practice (Goldewijk and Ramankutty 2004). However, land cover change has recently become a major concern for research on global warming and global change; it draws attention and has emerged as a research agenda for many researchers (Lambin et al. 2003). Wondie et al. (2011) analyzed LULC change of 
Simen Mountains National Park, a World Heritage Site in northwestern Ethiopia and linked to human interference and encroachment to the park.

LULC dynamics is an important landscape process capable of altering the fluxes of water, sediment, contaminants, and energy. Mainly caused by human, impact of land use on water resources availability is high. Degraded watersheds tend to accelerate overland flow reducing soil moisture and baseflow recharge and increases sediment detachment and transport. Various studies used land cover mapping tools and methods to understand land use changes, inventory of forest, and natural resources as well as understand the changes in the hydrologic behavior of watersheds (Getachew and Melesse 2012; Mango et al. 2011a, b; Wondie et al. 2011, 2012; Melesse and Jordan 2003; Mohamed et al. 2013).

The changes of land use are the result of the interaction between the socioeconomic conditions of the society, institutional and environmental factors added with population pressure, land use type, and climatic conditions. LULC analysis is also devoted to the relations between land use and the socioeconomic and biophysical variables that act as the driving forces of LULC change, associated with the intensification of agriculture, cattle production, and urbanization, could have a profound impact on the hydrological processes in small watersheds and at the regional level (Mendoza et al. 2002). Proper change detection in land cover types requires the spatial resolution of satellite images (Swinne and Veroustaete 2008; Yu et al. 2011).

Since LULC changes are products of prevailing interacting natural and anthropogenic factors (Fashona and Omojola 2005) and their utilization by man in time and space (Clevers 2004), the need to track the change pattern and areal extent of LULC in small-scale watersheds with Landsat imagery and to quantify the rate of change is a critical input for natural resource management policy decisions. Geospatial techniques are used to monitor the LULC dynamics and have an important role in natural resources conservation, management, monitoring, and assessment of catchment characteristics, for the study of hydrologic response and flow regime. GIS and remote sensing tools are used to understand the rate and magnitude of LULC change and to derive accurate and time-valued spatial distribution information (Carlson and Azofeifa 1999; Guerschman et al. 2003; Rogana and Chen 2004; Zsuzsanna et al. 2005).

In this chapter, detailed space-time scale LULC map is produced and the rate and magnitude of change is quantified. To this effect adequate amount of Earth's surface data are collected using remote sensing tools which provide an excellent source-updated LULC information and changes that can be extracted and analyzed efficiently (Bauer et al. 2003). Since the launch of the first remote sensing satellite (1972), multiresolution and multitemporal satellite data available in various data archives have been used as a base for various environmental studies including LULC change analysis and to present a reliable database for long-term change detection using Landsat imageries recorded in the last four decades using Multispectral Scanner (MSS), Thematic Mapper (TM), and Enhanced Thematic Mapper Plus (ETM+) sensors. 
As part of change detection analysis, image differencing with the principle of subtraction of images of two different time periods of the same location to evaluate the change pattern in different temporal levels (Dimyati 1995) is important to planners in monitoring the consequences of the change on the area to plan and assess the pattern and extent of the change, to model and predict the future level of change, and to analyze the driving forces of changes (Moshen 1999). Classified images are associated with errors, to reduce these errors, post-classification refinements are done using an error matrix approach. The error matrix is computed as the total number of correct class predictions divided by total number of cells (Verbyla 1986). Accuracy assessment of classified images is undertaken to verify the extent to which classified imagery is accurate, by using producers and users' accuracies assessment and Kappa statistics (Sexton et al. 2013). These assessments make it possible to correct conservative and optimistic biases in image classification due to misclassification of land cover classes. For this study, accuracy was assessed using the error matrix and the result validated using Kappa coefficient values. Congalton (1996) indicated that Kappa coefficient values greater than 0.80 show strong agreement, and between 0.40 and 0.80 as moderate agreement, and below 0.40 considered poor agreement.

\subsubsection{Land Use Change Issues}

Land is becoming a scarce resource due to immense agricultural and demographic pressure, which requires extraction of information on LULC and possibilities for their optimal use for selection, planning, and implementation of land use schemes to meet the increasing demands for basic human needs and welfare. It is also noted that LULC change studies are proven to be essential for the qualification and quantification of central environmental processes, environmental change and influence of environmental management on biodiversity, water budget, radiation budget, trace gas emissions, carbon cycling, livelihood (Verburg et al. 2002, 2004), urban and rural agricultural land loss (Lambin et al. 2003; Muzein 2008), and a wide range of socioeconomic and ecological processes (Ozbakir et al. 2007), which on the aggregate affects global environmental change and the biosphere (Fashona and Omojola 2005).

Land use and land cover are dynamic in nature and understanding the interaction and relationship of anthropogenic activities with the environment is essential (Prakasam 2010). The finding of many researches across abroad and particularly in the study basin about LULC change and driving forces in small and larger watersheds fails to explain either the length of time series of records or quality of the analysis while viewing the Earth from space, which is crucial to study the situations of rapid and often unrecorded land use change by which observations of the Earth from space provide objective information on human utilization of the landscape. 
There are different studies in the Rift valley basin and Bilate watershed, (the study area, Batena is the subwatershed of Bilate), southern Ethiopia; the effect of LULC changes and management practices in watershed hydrological responses (Kassa 2009), assessment of LULC dynamics and its impact on soil loss (Loppiso 2010), analysis of biomass degradation as an indicator of environmental challenge (Degelo 2007), and watershed modeling to understand catchment flow responses and the impact of catchment dynamics on runoff generation (Negash 2014). However, there is no detailed fine time scale and well-trained time series of LULC change study in small watersheds like Batena signifying the anthropogenic impact on the trend and rate of LULC change.

\subsubsection{Objectives}

The overall objective of the study is to quantify the LULC change trajectories with the available multitemporal Landsat imagery and to detect the rate and magnitude of change for a small rural area, Batena, in the Rift Valley Lakes Basin, Ethiopia.

The specific objectives of this study are to

1. identify the decadal LULC change at different spatial and temporal scales;

2. produce an LULC map of the area and identify the rate, nature, trend, and magnitude of change; and

3. assess the accuracy of the classification technique.

\subsection{Study Area and Datasets}

\subsubsection{Study Area Description}

The study watershed, Batena, is a $116.7 \mathrm{~km}^{2}$ rural watershed located in the mountainous part of Rift Valley lakes basin, southwestern part of Ethiopia (Fig. 4.1). The region is typified by steep to moderate hill slopes of dominantly clayey permeable soils, with insignificant areal coverage of Leptosols and Regosols.

The topography of Batena watershed signifies two distinct features; the highlands, ragged mountainous areas in the north most and northwest part of the watershed and lowlands in the eastern most part of the watershed. The altitude in the watershed ranges from $2063 \mathrm{~m}$ in the low lands up to $2947 \mathrm{~m}$ in the highlands. Topography of the watershed is mountainous, with an average slope exceeding $25 \%$ (4\% in the flat areas and more than $30 \%$ in the mountainous part of the area). The area has a bimodal rainfall pattern with high spatiotemporal variability. According to the FAO-UNESCO soil classification, the dominant soils in the watershed includes the high base status, high activity, and clay-enriched Chromic 


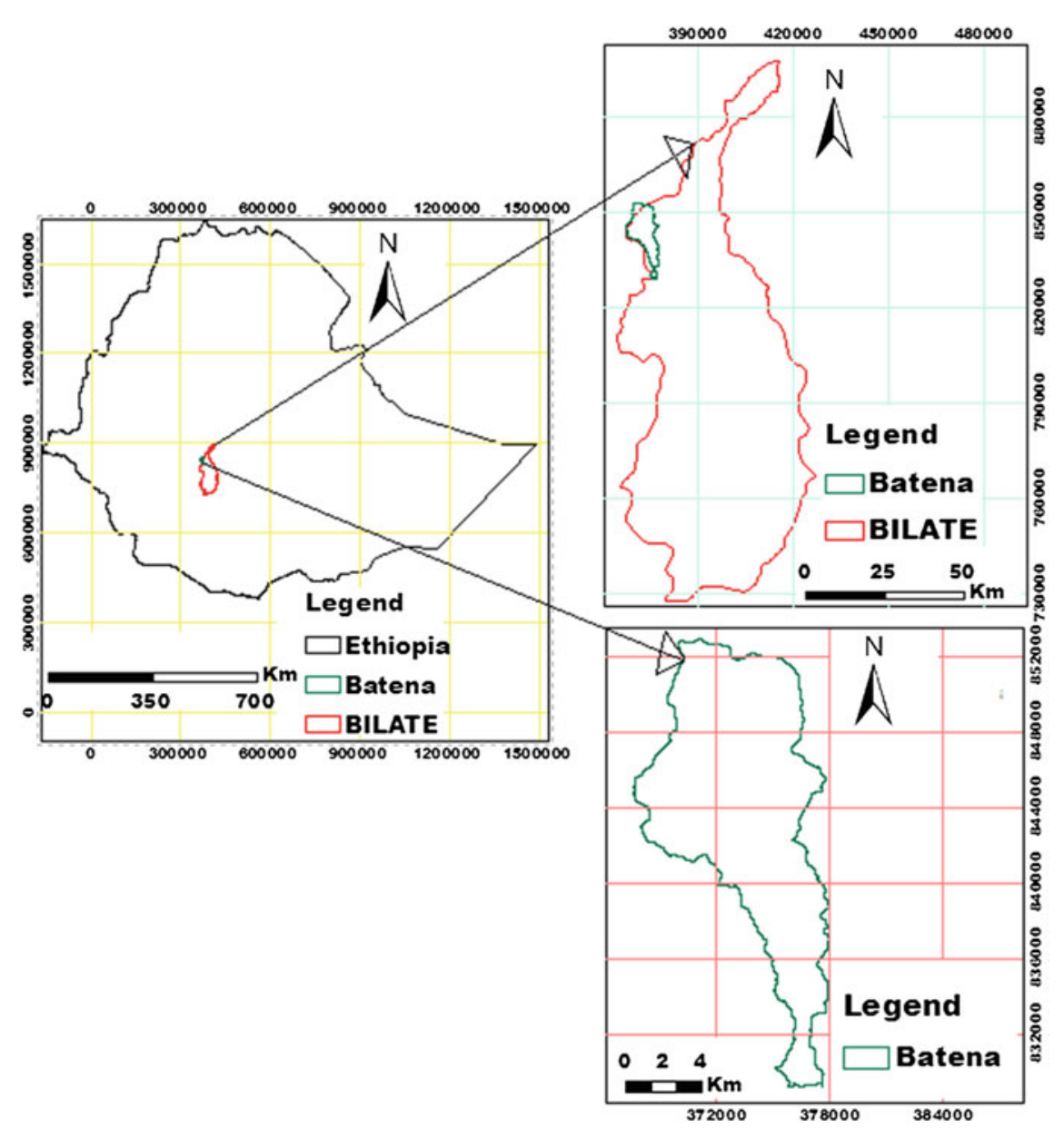

Fig. 4.1 Location of the study area

Luvisols with about $94.11 \%$ areal coverage and the deep, well-drained, low-activity, P fixation, and strongly structured, tropical soils with diffuse horizon boundaries (Humic Nitisols).

\subsubsection{Field Data Sampling and Design}

The field survey includes reconnaissance of the area and ground truthing to produce decadal LULC maps, spatial extent, and neighborhood features. The LULC change is analyzed by using WGS 1984 datum referenced remotely sensed medium resolution Landsat satellite from MSS, TM, and ETM+ sensors digital data. 
The Landsat satellites acquire imagery in a regular, tiled fashion, following the World Reference System (WRS1 for MSS, WRS2 for TM and ETM+). The MSS sensor provides the oldest and lowest quality Landsat data, from 1972 to present.

\subsection{Methods}

\subsubsection{Image Classification}

For proper image classification and change detection MSS, TM, and ETM+ images have passed through different pre- and post-classification and change detection steps including digital image processing for manipulation and interpretation of digital images, image resampling, image enhancement, spatial enhancement, radiometric, enhancement, spectral enhancement, and image transformation.

Image preprocessing: A series of sequential preprocessing operations including atmospheric correction or normalization, image registration, geometric correction, and masking (e.g., for clouds, water, irrelevant features) is important before image classification. The normalization of satellite imagery takes into account the combined, measurable reflectance of the atmosphere, aerosol scattering and absorption, and the Earth's surface. Geometric rectification of the imagery resamples or changes the pixel grid to fit that of a map projection or another reference image. This becomes especially important when scene to scene comparisons of individual pixels in applications such as change detection are being sought. Due to availability of longer date of acquisition of satellite images, the Landsat images are preferred, though their lower resolution may affect the level of information that can be extracted from the images.

Image resampling: MSS images have low spatial resolution but TM and ETM+ images have relatively higher resolution. For LULC change analysis with the different years of satellite imagery, date of data acquisition and resolution of images must be similar as much as possible. Therefore, the bands of MSS images were resampled to the higher spatial resolution before use for analysis.

Spatial Image Enhancement: Image enhancement process involves solely improving the appearance of imagery to assist in visual interpretation and analysis. Spatial Image enhancement method helps to increase spatial resolution of an image using the spatial enhancement techniques of resolution merge which enables to integrate imagery of different spatial resolution or pixels. Since a higher resolution imagery is a single band (panchromatic band with resolution of $15 \mathrm{~m}$ in ETM+ images) while multispectral imagery generally have a lower resolution (TM $30 \mathrm{~m}$ resolution). These techniques are often used to produce high resolution, multispectral imagery to improve the interpretability of the data by having color resolution information.

Radiometric Image Enhancement: As part of radiometric corrections, stripping and banding corrections have been made, which occurs if a detector goes out of adjustment; it provides readings consistently greater than or less than the other 
detectors for the same band over the same ground cover (Crippen 1989a). The effects of the atmosphere upon remotely sensed data are not considered errors, since they are part of the signal received by the sensing device (Bernstein 1983). This defect was corrected by conversion of radiance to reflectance. For the conversion of radiance to reflectance, the characteristics of the satellite images used have been known from header files of the image.

Spectral Image Enhancement: Principal Component analysis is used as a method of data compression, to produce uncorrelated output bands, to segregate noise components, and to reduce the dimensionality of data sets. It allows a redundant data to be compacted into none correlated and independent fewer bands of more interpretability than the source data. Principal Component bands produce more colorful color composite images than spectral color composite images because the data is uncorrelated (Richards 1999).

Image Transformation: Unlike to image enhancement operations which are applied only to single channel of data at a time, image transformation usually involves combined process of data from multiple spectral bands. Arithmetic operations are performed to combine and transform the original band to "new" image which better displays or highlights certain features in the scene. Tasseled cap transformation is used in the research for enhancing spectral information content of Landsat TM data. Tasseled cap transformation, especially optimizes data viewing for vegetation studies, is calculated from data of the related six TM bands. Three of the six tasseled cap transform bands are often used: band 1 (brightness, measure of soil), band 2 (greenness, measure of vegetation), and band 3 (wetness, interrelationship of soil, and canopy moisture). The tasseled cap transformed bands are layer stacked for analysis of LULC change. The layer stacked landsat images of 1973, 1984, 2003, and 2008 are radiometric enhanced for haze and noise reduction.

\subsubsection{Land Cover Mapping}

Field Sampling Design and Image Classification: Field sampling is made to validate land cover interpretation results from satellite images, for qualitative characteristic descriptions of each land use and land cover classes. For better accuracy image classification, it is found important to convert the Landsat radiance values to reflectance. To eliminate the effects of atmospheric scattering and absorption; and to increase the accuracy of surface-type classification, the Landsat digital number (DN) values were converted to top-of-atmosphere (TOA) reflectance. After converting Landsat radiance values to reflectance, their Normalized Difference Vegetation Index (NDVI) is calculated for both radiance values and TOA reflectance to evaluate the effects of converting processes. This is performed in a two-step procedure, first, by converting DN values to spectral radiance and second, by transferring the sensor-detected radiance into TOA reflectance. In the first stage, DN values of the sensor measurements are converted 
into spectral radiance measured by satellite sensors. In the second stage, the sensor-detected radiance is transferred into the ground surface reflectance.

To evaluate the effects of converting processes, NDVI is calculated for both radiance values and TOA reflectance of Landsat using the following formula:

$$
\mathrm{NDVI}=\frac{(\text { Band } 4-\text { Band } 3)}{\text { Band } 4+\text { Band } 3}
$$

where Band 4 is near-infrared and Band 3 is visible red reflectance or the NDVI can also calculate with this expanded form as:

$$
\mathrm{NDVI}=\frac{\mathrm{NIR}_{\text {ref }}-\mathrm{RED}_{\text {ref }}}{\mathrm{NIR}_{\text {ref }}+\mathrm{RED}_{\text {ref }}}
$$

where NDVI is a simple numerical indicator that can be used to analyze remote sensing measurement, $\mathrm{NIR}_{\text {ref }}$ is reflectance for vegetation at near-infrared spectral band, and $\mathrm{RED}_{\text {ref }}$ is reflectance for vegetation at red spectral band. Figure 4.2 shows the NDVI classes for the different land cover types.

Unsupervised Classification: Classification is the process of sorting pixels into a finite number of individual classes, or categories of data, based on their data file values using both unsupervised and supervised classification. Prior to supervised classification, unsupervised classification is done by taking the NDVI values using the Iterative Self-Organizing Data analysis (ISODATA) algorithm. Figure 4.3 shows results of the unsupervised classification. This technique repeatedly performs an entire classification with a standard deviation or distance threshold and recalculates statistics with minimum user inputs for locating clusters and also is relatively simple and has considerable intuitive appeal. The classic supervised and unsupervised classification techniques have been used successfully on medium to lower resolution imagery (imagery with pixel sizes of $5 \mathrm{~m}$ or larger), however, one of their significant disadvantages is that their statistical assumptions generally preclude their application to high resolution imagery. They are also hampered by the necessity for multiple bands to increase the accuracy of the classification.

Supervised Classification: Following the computer-automated unsupervised classification; supervised classification is performed on the selected classification scheme employing Bayesian maximum likelihood classifier (MLC). LULC maps are produced for the years 1973, 1984, 2003, and 2008 to investigate changes that occurred between these periods. The image classification accuracy depends on factors such as number of spectral bands in the imagery, target/background contrast, signature quality, ground truth information, and image quality.

A majority/minority analysis is used for smoothing the classification results. The accuracy of classification is carried out by means of a confusion matrix generated through geographic information system (GIS) overlay of the classified maps and the test samples. The image classification accuracy is further assessed by calculating the Kappa coefficient ' $k$ '. The kappa statistics is an estimate of measure of overall agreement between image data and the reference (ground truth) data. Essentially, 

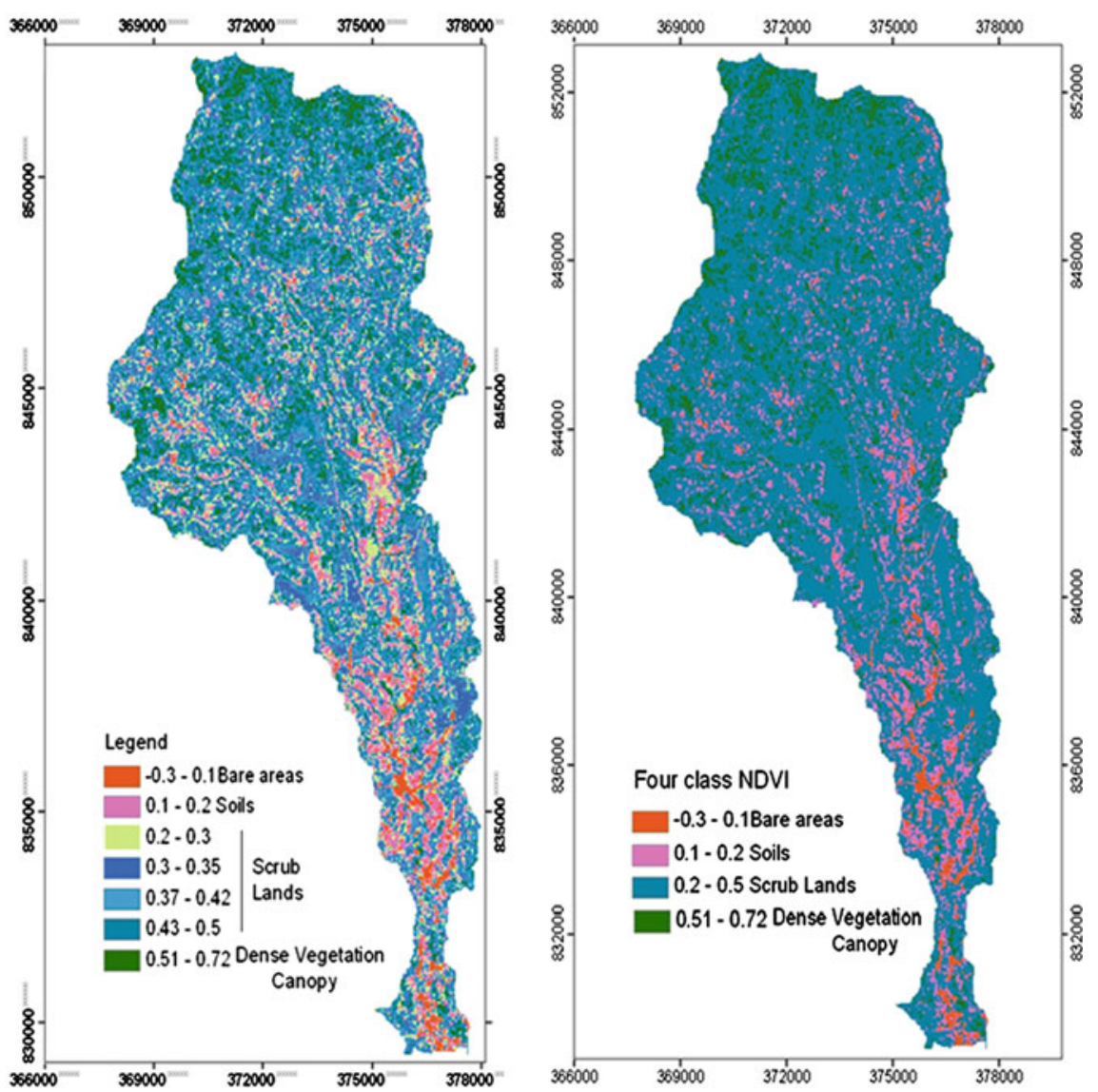

Fig. 4.2 Unsupervised classification with NDVI values (conversion of landsat radiance values to reflectance)

land cover change detection involves the ability to quantify temporal effects using multitemporal data sets. Remotely sensed data obtained from Earth orbiting satellites is an important data source for land cover change detection because of repetitive coverage at short intervals and consistent image quality (Singh 1989).

Land Use/Land Cover Change Detection: Change detection involves the use of multispectral data sets to discriminate area of land cover change between dates of imaging. Ideally, change detection procedures should involve data acquired by the same or similar sensor and be recorded using the same spatial resolution, viewing geometry, spectral bands, radiometric resolution, and the time of the day. Some aspects of change detection application using remote sensing are LULC change analysis, forest and vegetation change analysis, wetland change analysis, forest fire, and landscape change. Change detection techniques based on multispectral and multitemporal remotely sensed data have demonstrated a great potential as a means 
4 Multitemporal Land Use/Land Cover Change Detection ...
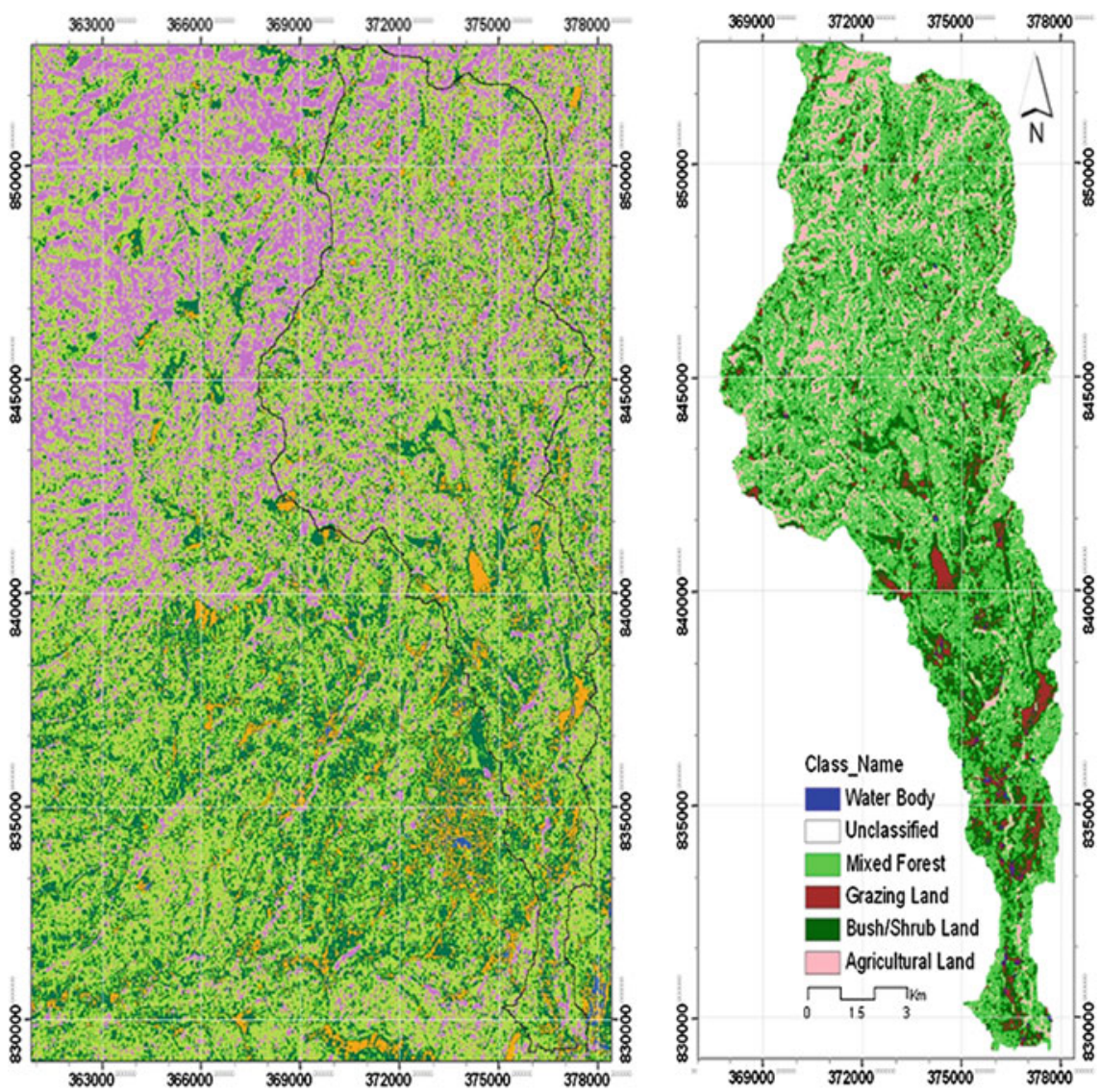

Fig. 4.3 Unsupervised classification false color composite of Batena (2008)

to understand landscape dynamics and to monitor differences in land use and land cover patterns over time, irrespective of the causal factors (Jensen 1996). Therefore, attempt is made in this study to quantify the magnitude of change and change rate, spatial distribution of change types, and change trajectories of land cover types. Accuracy assessment of change detection results are performed over the study periods from 1973 to 2008 . The most widely used change detection algorithm is the Post-Classification Comparison (PCC) which detects changes between hand-labeled region classes (Currit 2005; Petit et al. 2001). This technique provides detailed change trajectories between the two images. In addition, the independent classification processes reduce the impact of multitemporal effects due to atmosphere or sensor differences (Lu et al. 2004). The changed pixels extracted between the study period are used to define the "from-to" LULC class trend of change, the area coverage and their trajectories. Hienen and Lyon (1989) conducted a sensitivity analysis to calculate habitat index. 


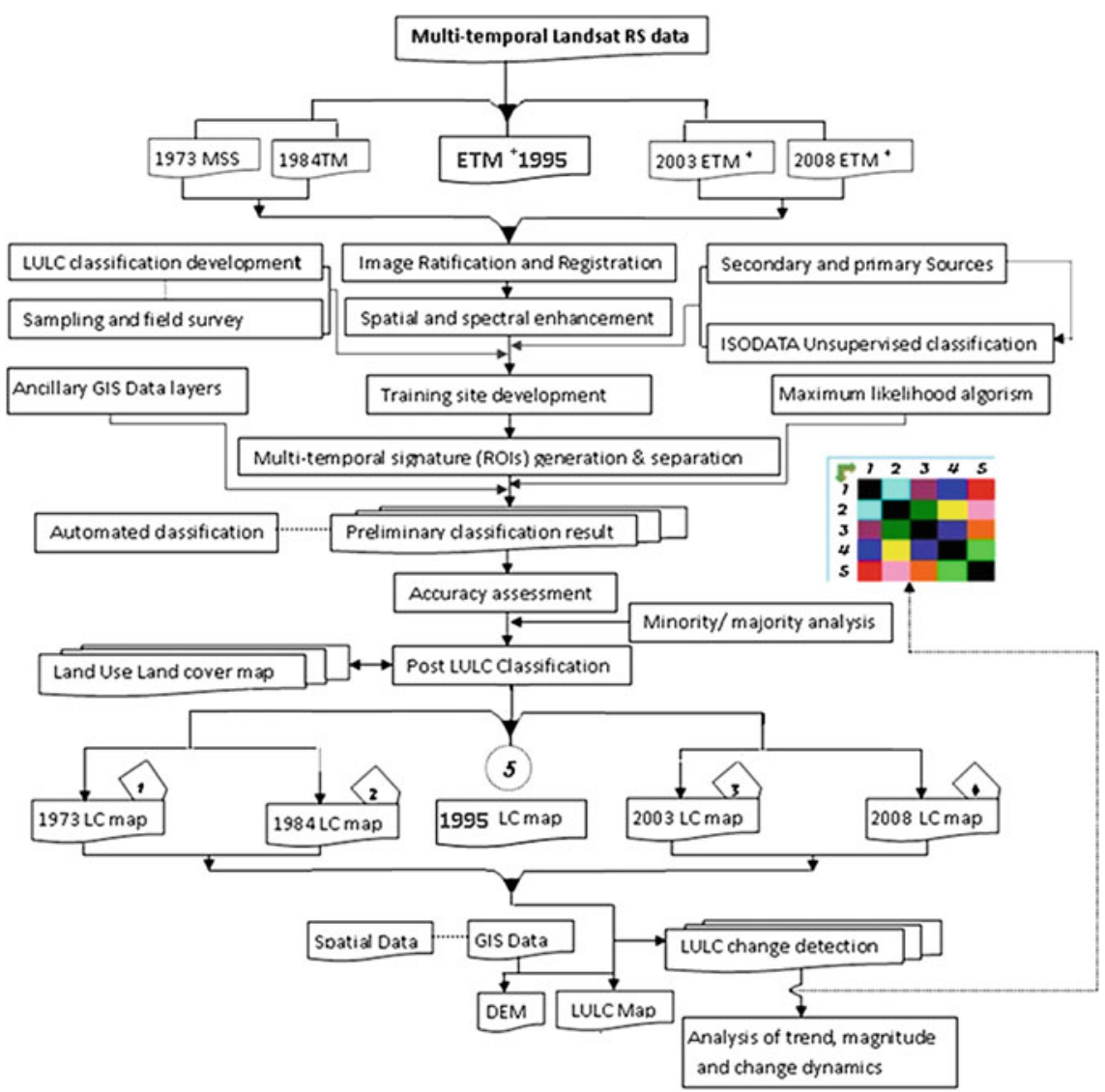

Fig. 4.4 General working conceptual framework

The general working step (Fig. 4.4) and LULC change quantification are described in a flowchart with high level of detail from the scratch; year of Landsat imagery and mapping false color unsupervised and supervised classification verified by accuracy assessment to land cover mapping and finally LULC change detection.

\subsection{Results and Discussions}

As per the field survey and output of Landsat imagery classification, the land cover for the watershed is mainly characterized by Grazing land, bush/Shrub land, sparsely populated semi-mixed forest on the mountainous part of the area and in line with the streams, dominantly cultivated agricultural land, and an insignificant areal coverage of water body. Supervised classification with the selected Bayesian 
Table 4.1 Description of the land use classes in the study area

\begin{tabular}{l|l}
\hline Class & Description \\
\hline $\begin{array}{l}\text { Agricultural } \\
\text { and }\end{array}$ & $\begin{array}{l}\text { It is the land cover under the crop cultivation of annual crops. Scattered } \\
\text { settlements surrounded by agricultural lands are classified as agricultural } \\
\text { lands, since the low spatial resolution landsat imagery fails to separate the } \\
\text { scattered rural settlements with agricultural lands }\end{array}$ \\
\hline Grazing land & $\begin{array}{l}\text { It is the area covered with both communal and private pasture lands which } \\
\text { retain the grass cover for a year and above. Here it includes the fallow lands } \\
\text { which stay without tillage more than a year in the area }\end{array}$ \\
\hline Scrub lands & $\begin{array}{l}\text { Land covered by shrubs, bushes, and young regeneration. It is the area of land } \\
\text { covered with short to dwarf tree species with spares to densely populated land } \\
\text { status. This includes the Accasia species: Accasia (Abysinica, Albida, } \\
\text { Ducerence, Melanoxylone, Senegal, Seal, and Saligna), Eucalyptus species, } \\
\text { and miscellaneous species }\end{array}$ \\
\hline Mixed forest & $\begin{array}{l}\text { It includes the area of land covered with sparsely populated forest, riverine } \\
\text { trees and artificially planted indigenous and nonindigenous groups of trees } \\
\text { like eucalyptus globules (Nech Bahiezaf), Eucalptus Comanduleses (Key } \\
\text { Bahirzaf), Eucalyptus Saligna (Girar Bahirzaf), Cordia Africana (Wanza), } \\
\text { Sasbania Sesban (Yemeno Zaf), etc }\end{array}$ \\
\hline
\end{tabular}

maximum likelihood classification scheme as a parametric decision rule and well-developed method from statistical decision theory has proved the presence of four land cover classes with their detailed property and water body (Table 4.1).

Maximum likelihood algorithm based image classification technique gave good results for digital change detection in land use/land cover classes. As per the field survey and output of Landsat imagery, the land cover for the watershed is mainly characterized by grazing land, bush land, semi-mixed forest, dominantly cultivated agricultural land, and an insignificant areal coverage of water body (Table 4.2).

Land Cover Change Detection: The images are acquired in one swath/scene 169/055 (path/row) covering the whole area of the Batena catchment. Images from the Landsat satellites have been acquired since 1972, with a variety of characteristics to consider and available through the GLCF/Global Land Cover Facility.

Satellite images of 1973, 1984, 1995, 2003, and 2005 were used to analyze the size of the land use classes through time. A decreasing trend is shown for the mixed forest and grazing land year after year and shrub lands have shown a changeable and fluctuating trend throughout the analysis periods. The spatial extent of agricultural areas has revealed an amplified response mainly at the expense of the mixed forest and grazing land. The degree of expansion for agricultural land is shown with 0.984 strong positive correlation coefficient (Fig. 4.5).

The change detection statistics table (Table 4.3) provides a detailed tabulation of changes between two classified images. The statistics tables list the initial state classes in the columns and the final state classes in the rows. This is required for a complete accounting of the distribution of pixels that changed classes. For each initial state class (that is, each column), the table indicates how these pixels were classified in the final state image. The Class Total row indicates the total number of pixels in each initial state class, and the Class Total column indicates the total 
G.T. Ayele et al.

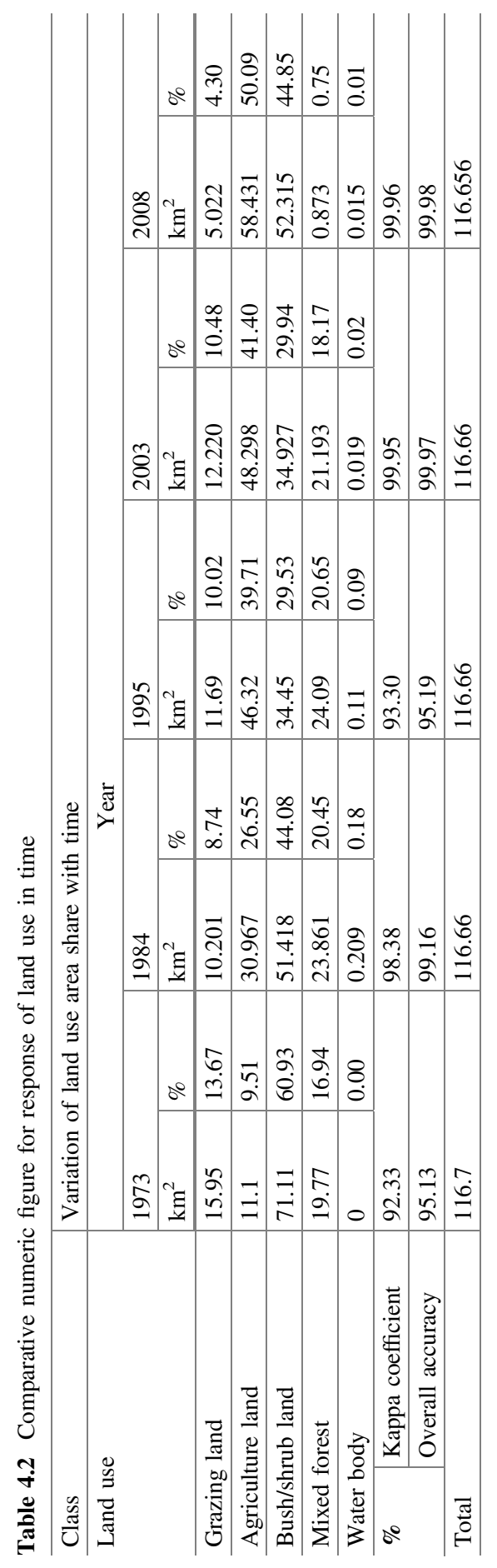


Multitemporal Land Use/Land Cover Change Detection ...

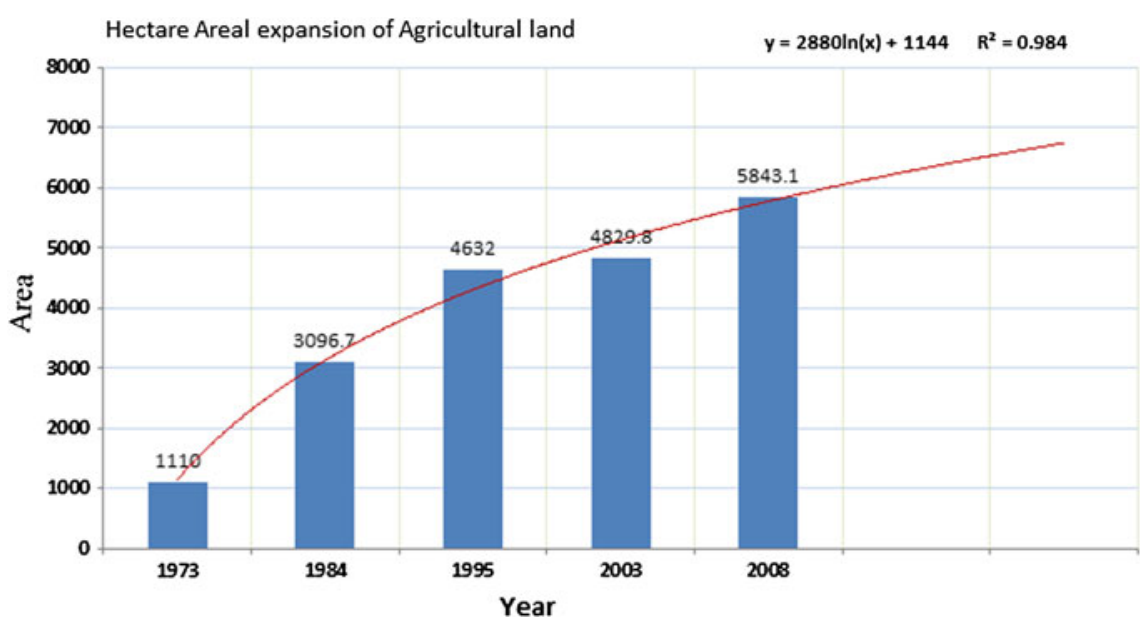

Fig. 4.5 Time response areal expansion of agricultural land (ha)

number of pixels in each final state class. The Row Total column is a class-by-class summation of all final state pixels that fell into the selected initial state classes. The Class Changes row indicates the total number of initial state pixels that changed classes. The Image Difference row is the difference in the total number of equivalently classed pixels in the two images, computed by subtracting the Initial State Class Totals from the Final State Class Totals. An Image Difference that is positive indicates that the class size increased and a negative indicates decrease in class size. Unchanged areas are shown in diagonal cells. In general, columns describe at what expense the new cover classes are established.

The Image Difference change detection statistics in Table 4.3 provides a detailed tabulation of changes between two classified images. The Image Difference is the

Table 4.3 Change detection statistics between final state (1984) and initial state image (1973) in hectare area measure

\begin{tabular}{|c|c|c|c|c|c|c|c|c|}
\hline & \multicolumn{8}{|c|}{ Final state image (1984) } \\
\hline \multirow[t]{9}{*}{$\begin{array}{l}\text { Initial state } \\
\text { image (1973) }\end{array}$} & Class & $\begin{array}{l}\text { Grazing } \\
\text { land }\end{array}$ & $\begin{array}{l}\text { Agricultural } \\
\text { land }\end{array}$ & $\begin{array}{l}\text { Bush/shrub } \\
\text { land }\end{array}$ & $\begin{array}{l}\text { Mixed } \\
\text { forest }\end{array}$ & $\begin{array}{l}\text { Water } \\
\text { body }\end{array}$ & $\begin{array}{l}\text { Row } \\
\text { total }\end{array}$ & $\begin{array}{l}\text { Class } \\
\text { total }\end{array}$ \\
\hline & Grazing land & 190 & 190 & 640 & 10 & 0 & 1030 & 1030 \\
\hline & $\begin{array}{l}\text { Agricultural } \\
\text { land }\end{array}$ & 300 & 530 & 1690 & 680 & 0 & 3200 & 3200 \\
\hline & $\begin{array}{l}\text { Bush/shrub } \\
\text { land }\end{array}$ & 980 & 300 & 3390 & 480 & 0 & 5150 & 5150 \\
\hline & Mixed forest & 130 & 80 & 1380 & 800 & 0 & 2390 & 2390 \\
\hline & Water body & 0 & 0 & 20 & 0 & 0 & 20 & 20 \\
\hline & Class total & 1590 & 1110 & 7110 & 1980 & 0 & 0 & 0 \\
\hline & $\begin{array}{l}\text { Class } \\
\text { changes }\end{array}$ & 1400 & 580 & 3720 & 1180 & 0 & 0 & 0 \\
\hline & $\begin{array}{l}\text { Image } \\
\text { difference }\end{array}$ & -560 & 2090 & -1960 & 410 & 20 & 0 & 0 \\
\hline
\end{tabular}


difference in the total number of equivalently classed pixels in the two images, computed by subtracting the Initial State Class Totals from the Final State Class Totals. An Image Difference that is positive indicates that the class size increased and a negative indicates decrease in class size. Agricultural land (+2090 ha), water body ( +20 ha), and mixed forest $(+410$ ha) have shown an increase in spatial neighborhood at the expense of scrub land (-1960 ha) and grazing land (-560 ha). Figure 4.6 shows the spatial map of the land cover for the study area in 1973 and 2008, a 35-year range.

A more extended and time series analysis of the change statistics is shown for all the years considered from 1973 to 2008. The areal expansion in hectare is tabulated (Table 4.4) for detailed change detection statistical analysis for years between final state image (2008) and initial state image (1973, 1984, 1995, and 2003).

(a)

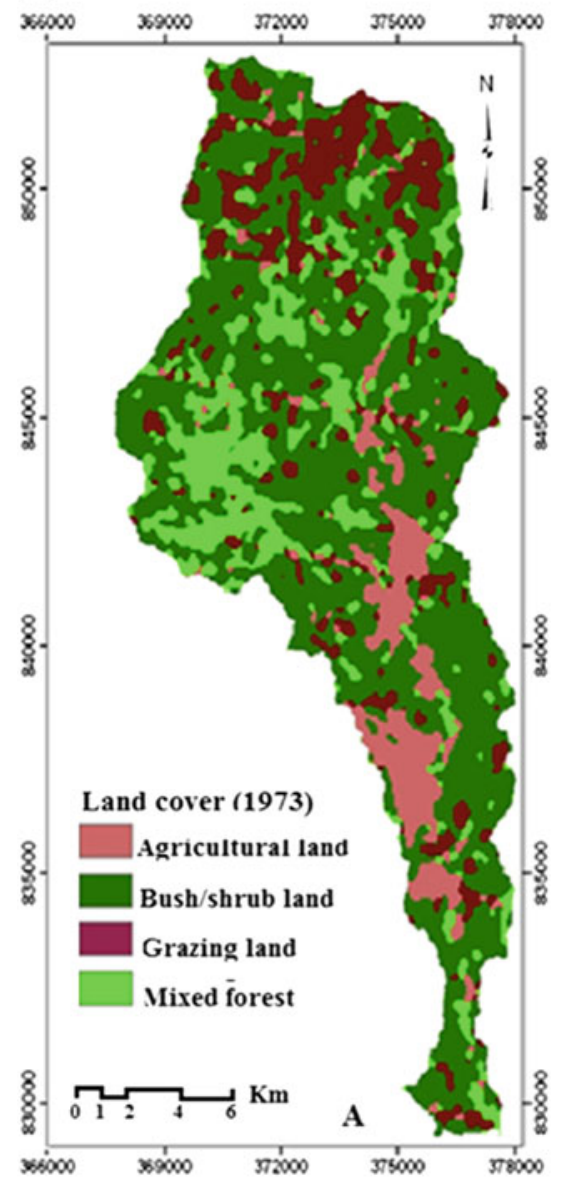

(b)

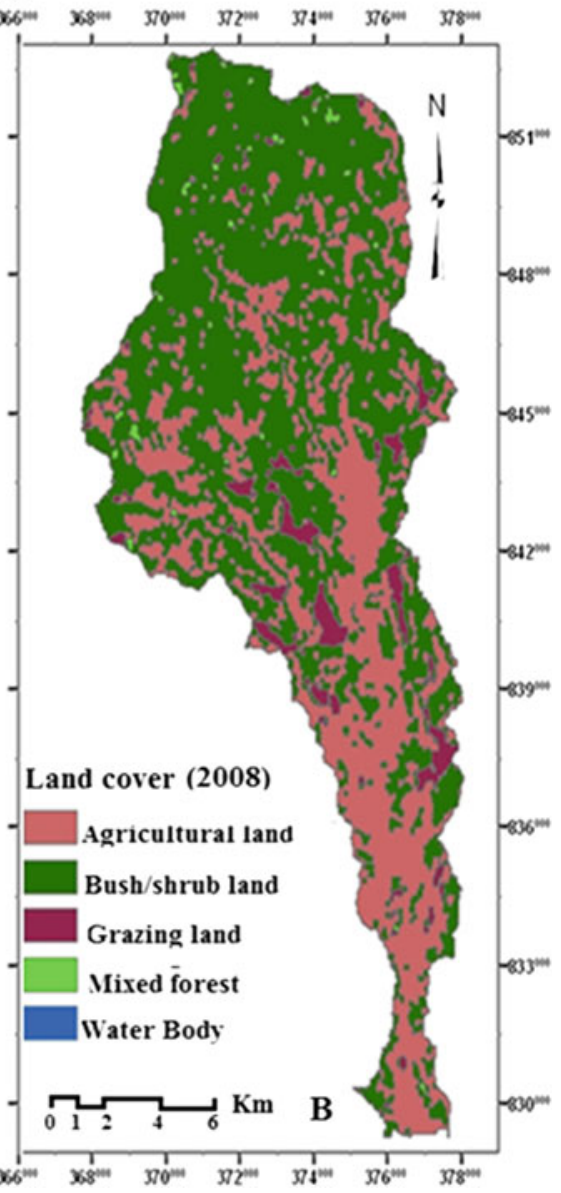

Fig. 4.6 Comparison of landsat land use/land cover map class and areal coverage for the years: a 1973 and b 2008 
4 Multitemporal Land Use/Land Cover Change Detection ...

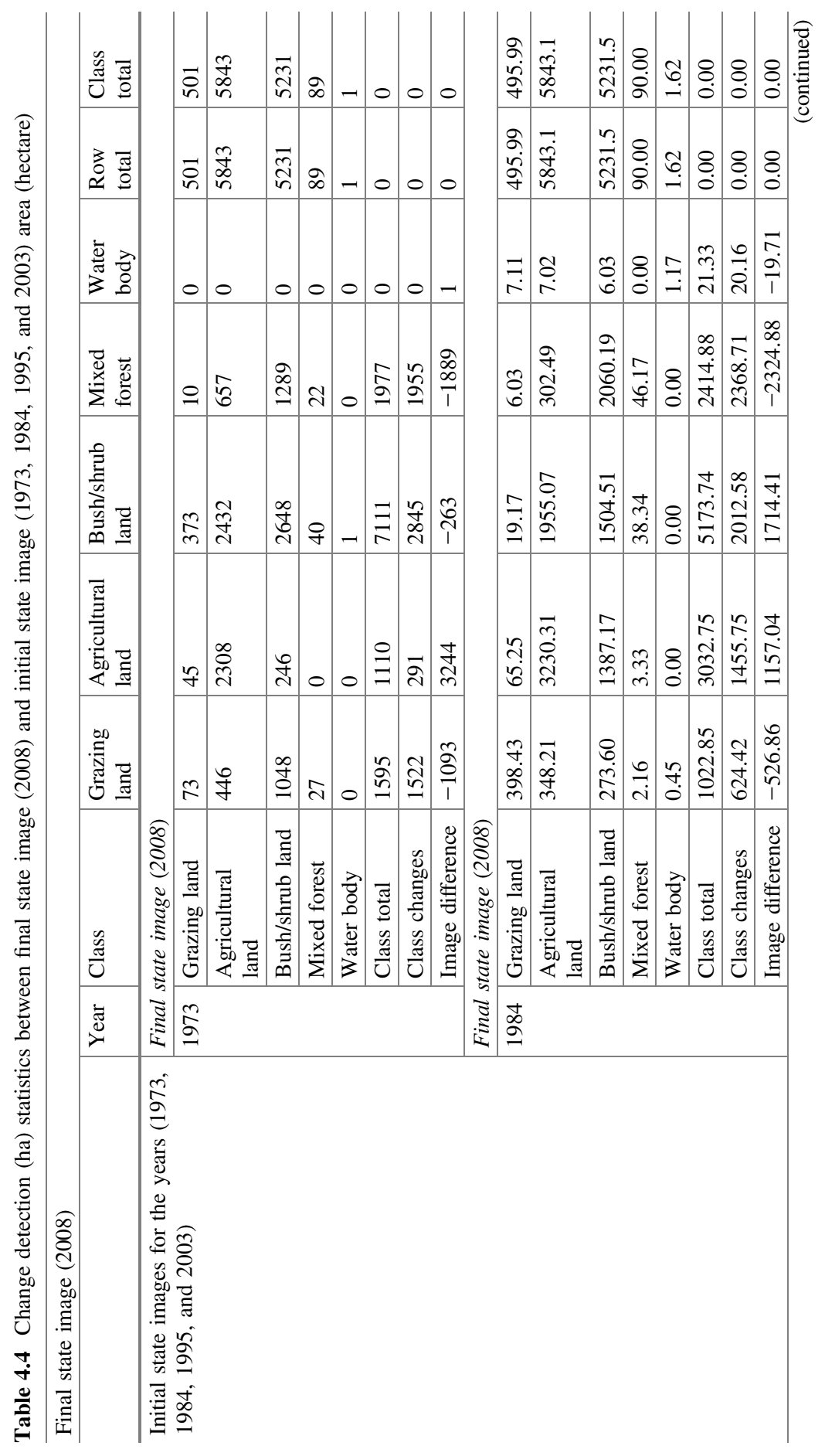


G.T. Ayele et al.

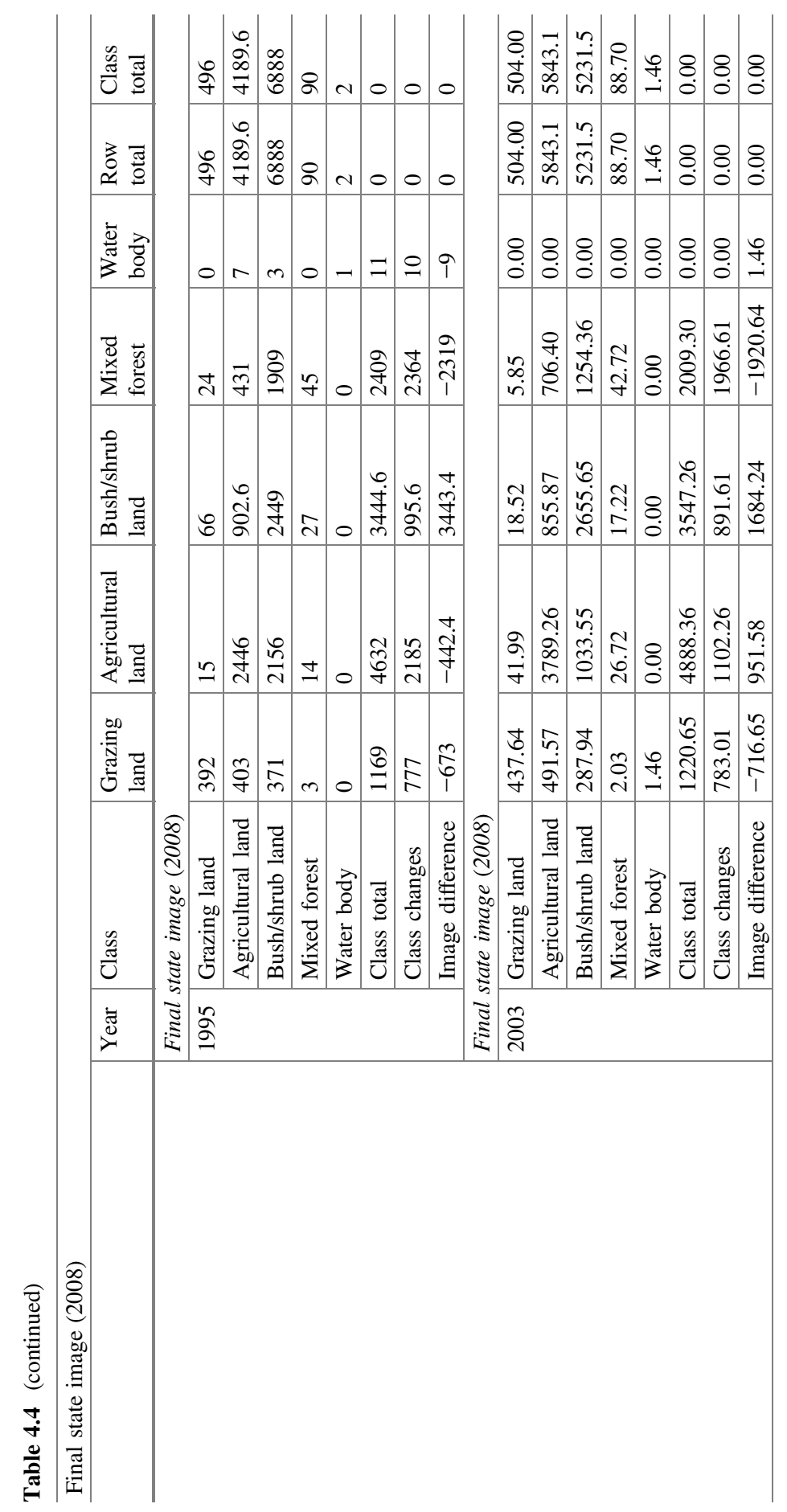


As shown in Table 4.4, for the 1973-2008 period, the land cover changes were grazing land $(-1093 \mathrm{ha})$, scrub land $(-263 \mathrm{ha})$, and mixed forest $(-1889 \mathrm{ha})$ to agricultural land $(+3244 \mathrm{ha})$ and water Body $(+1 \mathrm{ha})$. The areal extent of the agricultural land (2008) has increased to 3244 ha at the expense of 1093 ha of grazing land, 262 ha from scrub land, 1889 ha from mixed forest. Water body (2008) has increased to 1 hectare at the expense of the Scrub land.

\subsection{Conclusions and Recommendations}

\subsubsection{Conclusions}

As a key technical challenge, it is reasonable to expect the variation in LULC change in the river catchment of Batena in time due to which more robust projections can be made to alleviate the probable impacts of land use change on local climate and agricultural response pattern. To provide a road map of how to address the impact of this change, this chapter has addressed a number of specific research questions.

This study indicated that, Batena land cover from 1973 to 2008 showed rapid change with high growth in agricultural areas at the expense of the sparse and densely vegetated lands while grazing land has reduced marginally and water body is showing almost stagnant over time. Generally, the decadal analysis of LULC change shows a general decreasing trend for the mixed forest and grazing land year after year and scrub lands have shown a changeable trends throughout the analysis periods.

The magnitude of land use change varies considerably over space and time, reflecting the differences of landscape characteristics between locations in the catchment. To provide relevant conclusions and recommendations for policy makers, it is important to properly capture the major driving force to changes in LULC. Over the period of this analysis, it is shown that LULC change is the result of immediate and often radical human activities, natural effects over longer period of time, and complex interactions between several biophysical and socioeconomic conditions. Understanding the types and impacts of LULC change is an essential indicator for resource base analysis and development of effective and appropriate response strategies for sustainable management of natural resources in study area.

\subsubsection{Recommendation}

In this study, mapping of different types of land cover and change detection is carried out using digital image processing techniques. The spatial pattern and 
change detection in LULC could serve as guiding tool, in biodiversity conservation and environmental development.

The satellite imagery used for classifying land cover types and detecting land cover conditions should undergo atmospheric corrections by preprocessing satellite sensor imagery since the electromagnetic radiation signals received by the satellite sensors can be scattered and absorbed by the atmospheric gases and aerosols. The land use/cover type classification should be based from the conversion of Landsat sensor imagery into TOA reflectance.

There are some problems in getting highly accurate land use data, particularly in the mountainous landscapes of tropical climates. One of the main problems when generating land use maps from digital images is the confusion of spectral responses from different features. Discrimination of land cover types, including vegetation types, through the use of remote sensing techniques in the mountainous areas of Batena is a very difficult task because of the complex structure and composition of vegetation communities added with low spatial resolution of Landsat imagery. In addition, the mountain topography leads to a significant shadowing effect, which becomes a particular problem in the digital image processing. It is recommended to use one of the techniques to achieve improvement in digital classification by incorporation of ancillary data, such as a digital elevation model (DEM), geomorphometric variables (relief, convexity, slope, aspects, and incidence). DEM integration in image classification will increase the classification accuracy of digital data by describing the distribution of terrain components which contribute to spectral response, identify sites for fieldwork, and geographically stratify training areas or homogeneous regions.

Land use induced changes in the surface energy budget can affect climate across all scales: local, regional, and global. The combined impacts of land use and climate change are likely to dramatically affect natural resources and ecosystems. In view of such uncertainties, the coupling impact of land use and climate change should be seen through a simple feedback mechanism signifying the effect of their interaction to the rainfall-runoff generation and to characterize the impact of this change on small catchment hydrology.

Environmental problems have no boundaries and are interrelated. This chapter recommends further works to quantify the local vegetation cover change and its cumulative impact on regional and global climate changes.

Acknowledgments The authors acknowledge the International Water Management Institute (IWMI) "Nile Basin Development Challenge of the Consultative Group on International Agricultural Research program for water and food (NBDC-CGIAR-CPWF)", Horn of Africa Regional Environment Center and Network, Demand Driven Action Research Program (HoA-REC/N-DDAR), and the Ethiopian Ministry of Education for their financial support to conduct this research work. 


\section{References}

Bauer M, Yuan F, Saway K (2003) Multi-temporal landsat image classification and change analysis of land cover in the twin cities (Minnesota) metropolitan area. Workshop on the analysis of multi-temporal remote sensing images, Italy

Bernstein R (1983) Image geometry and rectification. Chapter 21 in manual of remote sensing. In: Colwell RN (eds) Falls church. American Society of Photogrammetry, Virginia

Carlson T, Azofeifa S (1999) Satellite remote sensing of land use changes in and around San Jose, Costa Rica. Remote Sens Environ 70:247-256

Clevers JB (2004) Land cover classification with the medium resolution imaging spectrometer (MERIS). In: EARSeLeProceedings 3

Congalton R (1996) A review of assessing the accuracy of classification of remotely sensed data. Remote Sens Environ 37:35-46

Crippen R (1989a) A simple spatial filtering routine for the cosmetic removal of scan-line noise from landsat tm p-tape imagery. Photogram Eng Remote Sens 55(3):327-331

Currit N (2005) Development of a remotely sensed, historical land-cover change data base forrural Chihuahua, Mexico. Int J Appl Earth Obs Geoinf 7:232-247

Degelo S (2007) Analysis of biomass degradation as an indicator of environmental challenge of Bilate watershed

Dimyati (1995) An analysis of landuse/landcover change using the combination of MSS landsat and land use map - case of Yogyakarta, Indonesia. Int J Remote Sens 17(5):913-944

Fashona M, Omojola A (2005) Climate change, human security and communal clashes in Nigeria. In: Int'l workshop on human security and climate change. Oslo, Norway

Getachew HE, Melesse AM (2012) Impact of land use /land cover change on the hydrology of Angereb Watershed, Ethiopia. Int J Water Sci 1(4):1-7. doi:10.5772/56266

Goldewijk K, Ramankutty NK (2004) Land cover change over the last three centuries due to human activities: the availability of new global data sets. Geojournal 61:335-344. Kluwer Academic Publishers, The Netherlands

Guerschman J, Paruelo J, Bela C, Giallorenzi M, Pacin F (2003) Land cover classification in the Argentine Pampas using multi-temporal Landsat TM data. Int J Remote Sens 24:3381-3402

Heinen JT, Lyon JG (1989) The effects of changing weighting factors on the calculation of wildlife habitat index values: a sensitivity analysis. Photogram Eng Remote Sens 55(10):1445-1447

Jensen JR (1996) Introductory digital processing: a remote sensing perspective, 2nd edn. Prentice-Hall, Upper Saddle River

Kassa T (2009) Watershed hydrological responses to changes in land use and land cover, and management practices at Hare Watershed, Ethiopia

Lambin EF, Geist HJ, Lepers E (2003) Dynamics of land-use and land-cover change in tropical regions. Ann Rev Environ Res 28:205-241

Loppiso S (2010) Assessment of land use land cover dynamics and its impact on soil loss: using GIS and remote sensing, in Shashogo Woreda, Southern Ethiopia

Lu D, Mausel P, Brondízio E, Moran E (2004) Change detection techniques. Int J Remote Sens 25:2365-2401

Lupo F, Reginster I, Lambin EF (2001) Monitoring land-cover changes in West Africa with SPOT vegetation: impact of natural disasters in 1998-1999. Int J Remote Sens 22:2633-2639

Mango L, Melesse AM, McClain ME, Gann D, Setegn SG (2011a) Land use and climate change impacts on the hydrology of the upper Mara River Basin, Kenya: results of a modeling study to support better resource management, special issue: climate, weather and hydrology of East African highlands. Hydrol Earth Syst Sci 15:2245-2258. doi:10.5194/hess-15-2245-2011

Mango L, Melesse AM, McClain ME, Gann D, Setegn SG (2011b) Hydro-meteorology and water budget of Mara River basin, Kenya: a land use change scenarios analysis, In: Melesse A (ed) Nile River basin: hydrology, climate and water use. Springer Science Publisher, Chapter 2, pp 39-68. doi:10.1007/978-94-007-0689-7_2 
Melesse AM, Jordan JD (2003) Spatially distributed watershed mapping and modeling: land cover and microclimate mapping using landsat imagery part 1. J Spat Hydrol (e-journal) 3(2):1-29

Mendoza M, Bocco G, Bravo B (2002) Spatial prediction in hydrology: status and implication in the estimation of hydrological processes for applied research. Prog Phys Geogr 26(3):319-338

Mohammed H, Alamirew A, Assen M, Melesse AM (2013) Spatiotemporal mapping of land cover in Lake Hardibo Drainage Basin, Northeast Ethiopia: 1957-2007. Water conservation: practices, challenges and future implications. Nova Publishers, New York, pp 147-164

Moshen A (1999) Environmental landuse change detection and assessment using multi-temporal satelitte imageries. Zanjan University

Muzein B (2008) Remote sensing and gis for landcover/landuse change detection and analysis in the semi-natural ecosystem and agriculture landscapes of the Central Ethiopian Rift Valley. Fakultät Forst- Geo-und Hydrowissenschaften Institut Fernerkundung

Negash W (2014) Catchment dynamics and its impact on runoff generation: coupling watershed modelling and statistical analysis to detect catchment responses. Int $\mathbf{J}$ stat Anal Detect Catchment Responses 6:73-87

Ozbakir B, Bayram B, Acar U, Uzar M, Baz I, Karaz I (2007) Synergy between shoreline change detection and social profile of waterfront zones: a case study in Istanbul. In: Conference paper at the international conference for photogrammetry and remote sensing, Istanbul, Turkey 16-18 May

Petit C, Scudder T, Lambin E (2001) Quantifying processes of land-cover change by remote sensing: resettlement and rapid land-cover changes in southeastern Zambia. Int J Remote Sens 22:3435-3456

Prakasam C (2010) Land use and land cover change detection through remote sensing approach: a case study of Kodaikanal taluk, Tamilnadu. Int J Geomatics Geosci 1(2):189-206

Richards J (1999) Remote sensing digital image analysis: an introduction. Springer, Berlin, p 240

Rogana J, Chen D (2004) Remote sensing technology for mapping and monitoring land-cover and landuse change. Prog Plann 61:301-325

Sexton JO, Urban DL, Donohue MJ, Song C (2013) Long-term land cover dynamics by multi-temporal classification across the landsat-5 record. J Remote Sens Environ 128:246-258

Singh A (1989) Digital change detection techniques using remotely-sensed data. Int J Remote Sens 10(6):989-1003

Swinne E, Veroustaete F (2008) Extending the SPOT-VEGETATION NDV timeseries (19982006) back in time with NOAA-AVHRR data (1985-1998) for southern Africa. IEEE Trans Geosci Remote Sens 46(2):558-572

Tiwari MK, Saxena A (2011) Change detection of land use/landcover pattern in an around Mandideep and Obedullaganj area, using remote sensing and GIS. Int J Technol Eng Syst 2 (3):398-402

Verburg P, Schot P, Dijst M, Veldkamp (2004) Lan duse change modelling: current practices and research priorities. Geo Journal 51(4):309-324

Verburg P, Soepboer W, Veldkamp A, Limpiada R, Espaldon V, Mastura S (2002) Modelling the spatial dynamics of land use: the CLUE-S model. Environ Manage 30(3):391-405

Verbyla (1986) Potential prediction bias in regression and discriminate analysis. Can J Forest Res 16:1255-1257

Wondie M, Scrhneider W, Melesse AM, Teketay D (2011) Spatial and temporal land cover changes in the Simen mountains national park, a world heritage site in Northwestern Ethiopia. Remote Sens 3:752-766. doi:10.3390/rs3040752

Wondie M, Schneider W, Melesse AM, Teketay D (2012) Relationship among environmental variables and land cover in the Simen Mountains national park, a world heritage site in Northern Ethiopia. Int J Remote Sens Appl (IJRSA) 2(2):36-43

Yu W, Gu S, Zhao XQ, Xiao J, Tang Y, Fang J, Jiang S (2011) High positive correlation between soil temperature and NDVI from 1982 to 2006 in alpine meadow of the three river sources region of Qinghai-Tibetan plateau. Int J Appl Earth Obs Geoinf 13(4):528-535

Zsuzsanna D, Bartholy J, Pongracz R, Barcza Z (2005) Analysis of landuse/land-cover change in the Carpathian region based on remote sensing techniques. Phys Chem Earth 30:109-115 